\title{
Formation and utility of reactive ketene intermediates under continuous flow conditions
}

\author{
Harry R. Smallman a, Jamie A. Leitch a, Tom McBride ${ }^{\text {b }}$, Steven V. Ley ${ }^{c}{ }^{\text {* }}$, \\ Duncan L. Browne ${ }^{\text {a, ** }}$ \\ a Department of Pharmaceutical and Biological Chemistry, University College London, School of Pharmacy, 29-39 Brunswick Square, WC1N 1AX, UK \\ ${ }^{\mathrm{b}}$ Cardiff Catalysis Institute, School of Chemistry, Cardiff University, Main Building, Park Place, Cardiff, CF10 3AT, UK \\ ${ }^{\mathrm{c}}$ Yusuf Hamied Department of Chemistry, University of Cambridge, Lensfield Road, Cambridge, CB2 1EW, UK
}

\section{A R T I C L E I N F O}

\section{Article history:}

Received 7 May 2021

Received in revised form

11 June 2021

Accepted 15 June 2021

Available online 24 June 2021

\section{Keywords:}

Reactive intermediates

Continuous flow

Ketene

Acyl-ketene

Photochemistry
A B S T R A C T
Continuous flow systems offer unique benefits in the generation and manipulation of sensitive reactive
intermediates such as ketenes. To this end, the last decade has witnessed the development of continuous
flow methods for the generation of ketenes by means of chemical, thermal, and photochemical activation
modes. This perspective covers these advances and the downstream reactivity of ketenes in continuous
flow technology.
@) 2021 The Author(s). Published by Elsevier Ltd. This is an open access article under the CC BY license (http://creativecommons.org/licenses/by/4.0/).

\section{Ketenes in organic synthesis}

Many transformations in organic synthesis deliver the desired product through reactive intermediate species. These are usually short lived, high energy, highly reactive molecules, which in turn renders their isolation and formal characterisation challenging. Despite this, these species can be detected spectroscopically or identified indirectly through interception with an appropriate chemical trap. Ketenes are typical examples of these reactive intermediates and may be formed in a variety of ways through reactivity of various reagents with appropriate precursor substrates, by dissociation of certain organic compounds, or by promotion of molecules to excited states by absorption of light or interaction with high-energy radiation [1-3].

Whilst an intermediate 'ketene species' was first postulated in 1901 by Wedekind [4], it was not until 1905 that Staudinger first reported the discovery and isolation of diphenylketene, the first example of a new family of reactive intermediates of this type. This stable ketene, a low melting point solid, was obtained through the

\footnotetext{
* Corresponding authors.

E-mail addresses: svl1000@cam.ac.uk (S.V. Ley), duncan.browne@ucl.ac.uk (D.L. Browne).
}

zinc-mediated dehalogenation of $\alpha$-chlorodiphenylacetyl chloride (Scheme 1A) [2]. Over the following two years - after the initial discovery - Staudinger reported a wide range of reactions of ketenes including: $[2+2]$ self-dimerization; cycloadditions to form $\beta$ lactams (Staudinger synthesis); and cycloadditions to form $\beta$-lactones [5,6] (Scheme 1A). Staudinger pursued this ketene chemistry for the next 20 years before later focusing on polymer chemistry, for which he obtained the Nobel Prize in 1953 [7].

Over a century after Staudinger's initial discoveries, ketenes still feature as powerful synthetic building blocks, especially in acylation methodology. Whilst the acylation of amines and alcohols to give amides and esters remains one of the most frequently used processes in many drug discovery and development programmes [8], these reactions typically require the use of stoichiometric coupling reagents or the use of reactive, moisture sensitive components such as acyl chlorides. Consequently, the generation and use of reactive ketene intermediates can offer more attractive, cleaner, and safer alternatives to the formation of these important products. Further to this, ketene species have been employed as key intermediates in numerous total syntheses of complex natural product architectures. For example, in 2016, Reisman and coworkers reported the first enantioselective total synthesis of the cytotoxic natural product, (+)-psiguadial B. The formation of the 


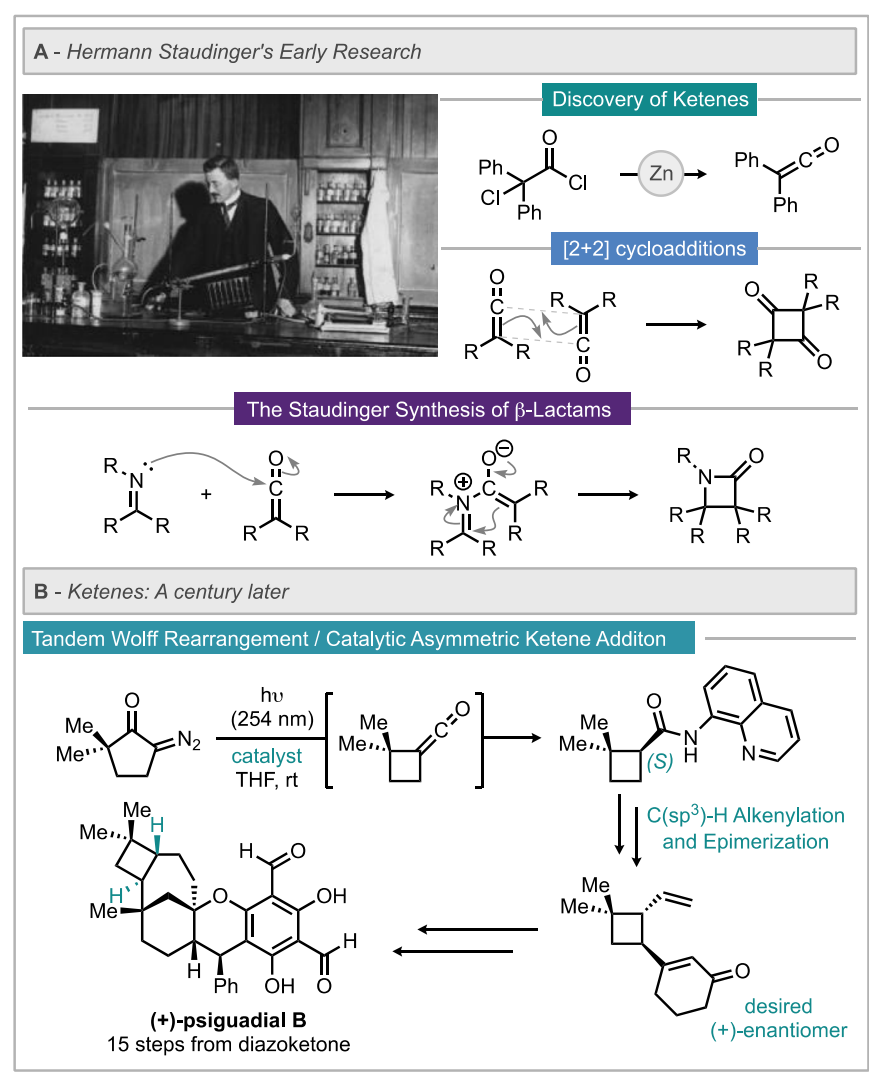

Scheme 1. Ketenes as reactive intermediates - from discovery through to contemporary uses.

enantioenriched amide was prepared directly from the photolysis of the diazoketone to form the cyclobutane ketene intermediate which was then intercepted by 8-aminoquinoline in the presence of a chiral catalyst en route to the natural product (Scheme 1B) [9].

There have been many excellent surveys and reviews detailing the various reactions of ketenes, including their history [7], synthesis of $\beta$-lactams by $[2+2]$ cycloadditions with imines [10], preparation of ketene dimers [11], catalytic reactions including Lewis base catalysed reactions [12,13], asymmetric processes using ketenes [14], and use in the formation of $\beta$-lactones $[15,16]$. This perspective focuses on the continuous flow generation of reactive ketenes for organic synthesis programmes.

\section{Flow chemistry as an enabling technology in organic synthesis}

Continuous flow processing is rapidly growing in the academic, pharmaceutical and fine chemical sectors for numerous reasons including favourable safety profiles, efficient mixing, enhanced heat and mass transfer, access to extreme reaction conditions, reproducibility and scale up, in-line workups and automated operation $[17,18]$. Over the last 15 years or so, the generation and use of reactive intermediates - such as ketenes - have become commonplace targets for study in contemporary continuous flow programmes. These continuous alternatives improve reaction control using parameters such as flow rate, residence time, temperature, and in-line analysis permitting the rapid and quantitative

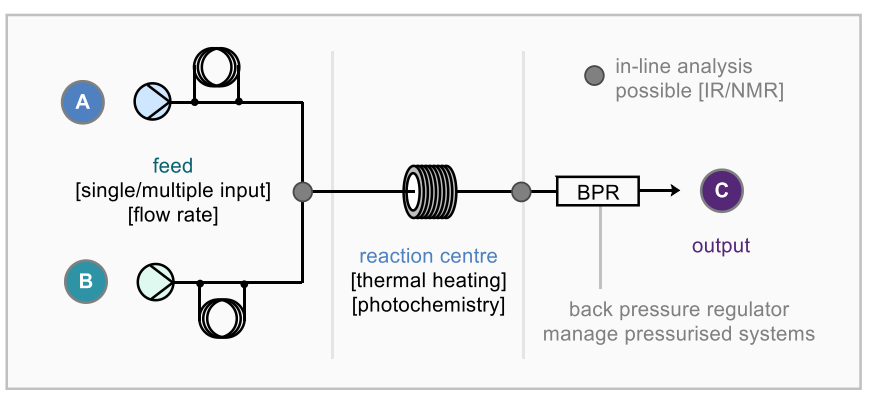

Scheme 2. Continuous flow as an enabling technology in organic synthesis.

generation and safe use of reactive intermediates [19]. Scheme 2 shows a simplified diagram of a flow set up which will be used throughout this perspective.

The following sections highlight recent endeavours to generate these reactive ketene intermediates under a continuous flow regime, employing chemical, thermal, microwave-assisted, and photochemical conditions for their generation.

\section{Chemical generation of ketenes in flow}

The use of prepacked columns containing powdered zinc metal was explored by Ley and Hafner to bring about a continuous flow dehalogenation process for the in situ generation of reactive ketenes (Scheme 3) $[19,20]$. The authors pre-activated the zinc

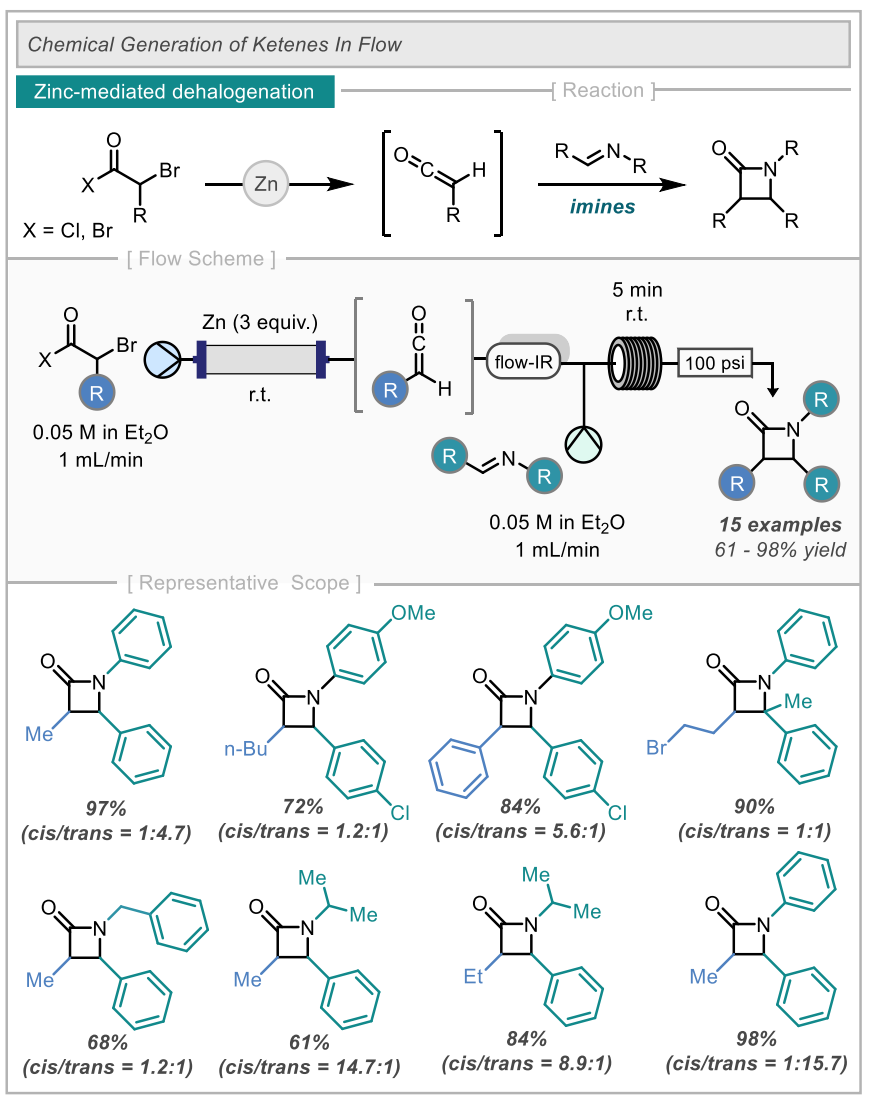

Scheme 3. Continuous flow zinc-mediated generation of ketenes in flow and their application to $\beta$-lactam synthesis. 
powder with $\mathrm{HCl}_{(\mathrm{aq})}$ and dispersed the powder into a columnpacked solid suspension of zinc ( 3 equiv.) and glass beads $(<106 \mu \mathrm{m})(1: 2)$. A solution of $\alpha$-bromoacyl bromides in THF was passed through a zinc-packed column to generate the corresponding ketenes in situ. To determine the formation of the ketene product an in-line IR spectrometer was employed, showing a characteristic IR band at around $2100 \mathrm{~cm}^{-1}$. The in situ-generated ketene species was also additionally identified by trapping with p-toluidine as a model nucleophile to give the expected amide product in $68 \%$ yield. As no observable side products were observed by IR, clean conversion was thereby suggested. The procedure was subsequently used to explore the ketene reactivity in a $[2+2]$ cycloaddition reaction with imines to form $\beta$-lactams. Further finetuning of the flow reaction conditions - to suppress ketene polymerisation - revealed that optimum yields and conversion were achieved using 1.5 equivalents of ketene at a concentration of $0.05 \mathrm{M}$, diethyl ether as solvent and reacting the output stream of ketene directly with the imine (also dissolved in diethyl ether). Using this method, 15 examples of a variety of $\beta$-lactams were reported in good to excellent yields (61-98\%).

Ketenes can be generated chemically using a base with a suitable ketene precursor. In 2015, Sörensen and co-workers at AstraZeneca, employed the use of $\mathrm{N}$-methylpiperidine to facilitate deprotonation at the alpha position of an acyl chloride precursor to generate the corresponding ketene intermediate, which was subsequently trapped with $N$-benzyl methyl imine, leading to the formation of the spiroazetidinone (Scheme 4) [21]. For this methodology to effectively work, the reactive ketene species was required to be produced and consumed as soon as possible. For example, premixing of the acid chloride with the amine base before entering the flow system delivered none of the desired product (presumably due to ketene formation and subsequent oligomerisation). By introducing the starting materials as three separate

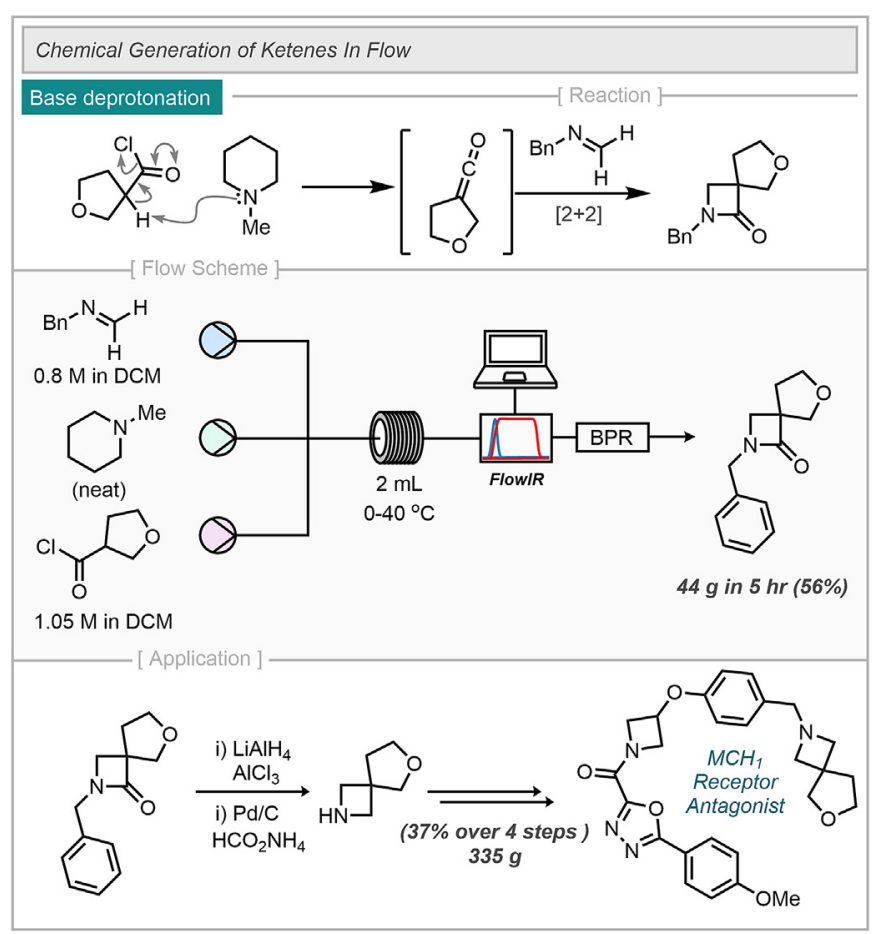

Scheme 4. Continuous flow base-mediated ketene formation and subsequent $[2+2]$ cycloaddition. streams, the desired spiroazetidinone was obtained in 56\% yield, with $44 \mathrm{~g}$ of product being produced over a 5 -h continuous reaction run. This intermediate was then utilised as a key starting material in the preparation of a $\mathrm{MCH}_{1}$ receptor antagonist.

Over recent years there has been a resurgence in the development of reaction systems that enable the construction of small carbo- and hetero-cyclic rings [22]. This has been largely driven by increased interest from the pharmaceutical and agrochemical industries. When compared to ketenes, the analogous more reactive keteneiminium salts can be especially useful for the generation of substituted cyclobutanones through $[2+2]$ cycloadditions with alkenes. In 2017, Ley and colleagues developed a continuous flow process to generate the keteneiminium salts, and in turn access small ring molecules through adaptation of a procedure first pioneered by Ghosez [23]. The system required application of a tubein-tube membrane reactor as a gas-feeding unit to overcome reactive gas handling issues. Using this tube-in-tube reactor, the controlled dosing of ethene gas across the gas permeable inner

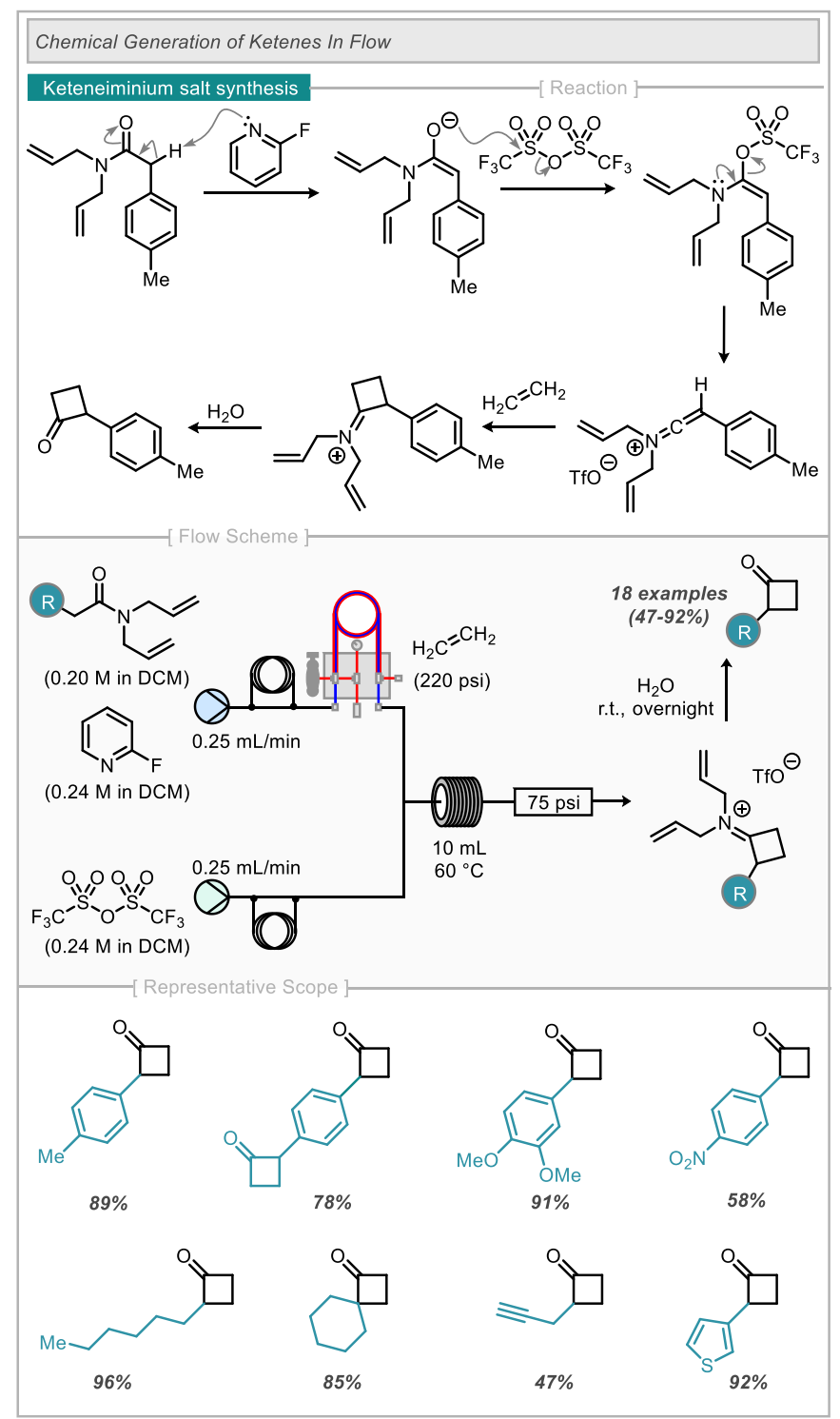

Scheme 5. Generation of keteneminium salts in continuous flow. 


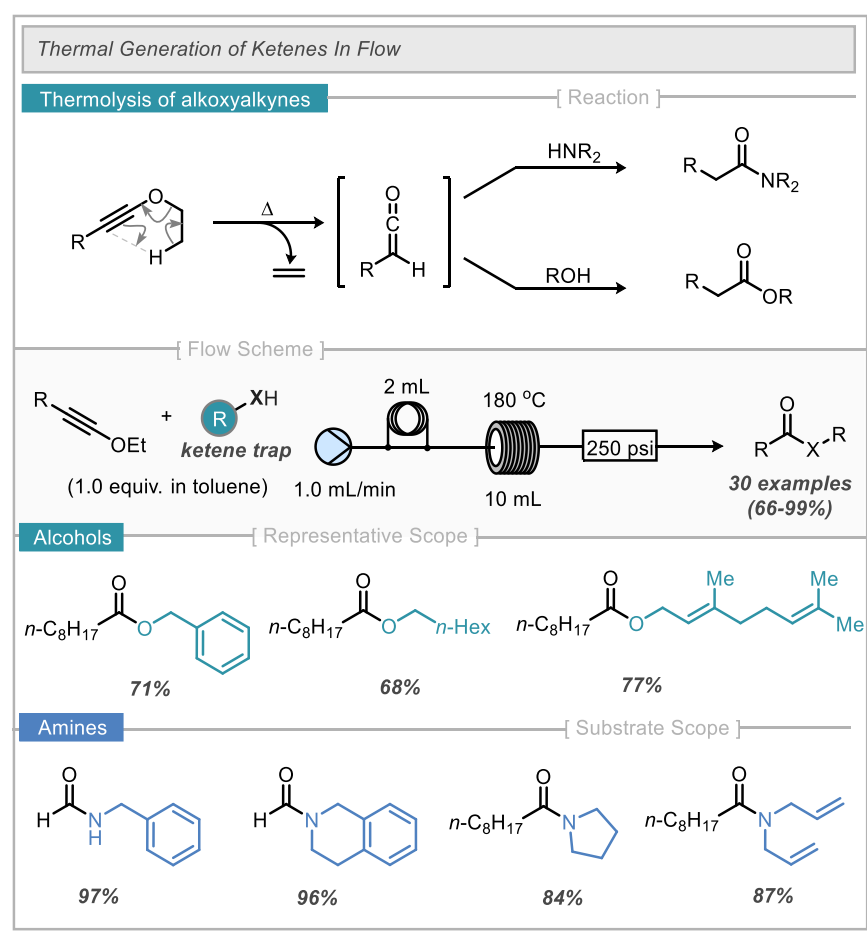

Scheme 6. Thermal generation of ketenes from alkoxyalkynes.

membrane was possible, which after a $[2+2]$ cycloaddition with a keteneiminium salt and in situ hydrolysis gave the corresponding cyclobutanone constructs in an efficient multi-step process (Scheme 5) [24]. The presence of both electron rich and electron poor substituents were well tolerated in the reaction, giving good yields of product. A range of heteroaromatics, as well as aliphatic examples, were exemplified showing tolerance to halogen and ester functionalities. Finally, to showcase the robustness of this procedure, a scale up reaction was also demonstrated where $3.92 \mathrm{~g}$ of a thiophene-appended cyclobutanone was prepared.

\section{Thermal generation of ketenes in flow}

Simple thermal activation of carefully designed precursors can lead to the formation of reactive ketene intermediates, obviating the need for chemical activation, which itself often generates stoichiometric waste. This concept was first applied in continuous fashion by Whitby and co-workers, in 2015. The researchers exploited the thermolysis of alkoxyalkynes (at $180{ }^{\circ} \mathrm{C}$ ) to generate ketenes (Scheme 6). The thermal sigmatropic rearrangement offered the opportunity for clean generation of ketenes with the only by-product being a low molecular weight, volatile alkene [25]. The authors employed this method for the preparation of a library of $30 \beta$-keto esters and $\beta$-keto amines in good to excellent yields. Notably, the volatile alkene by-product could be easily removed on workup thus simplifying the purification process and reaction profile.

Ketenes can be substituted with a variety of different functional groups, one particularly useful variant being acylketenes [26]. First reported by Wilsmore and Chick in 1908, acylketenes have become widely used throughout organic synthesis and they can be generated in a number of different ways from a broad range of precursors [27]. Acylketenes exhibit complementary reactivity to their nonacyl congeners, thus permitting access to a range of different reactivity. In 2019, Browne and co-workers demonstrated that thermolysis of 1,3-dioxinones, notably using the commercially available precursor 2,2,6-trimethyl-4-H-1,3-dioxin-4-one (TMD), could provide smooth access to acylketene intermediates (Scheme 7) [28]. In this case, a pressurised continuous flow system facilitated the exploration of different attributes of acylketene chemistry including the use of low boiling point solvents such as ethyl acetate and acetone as well as a variety of low-boiling alcoholic solvents as nucleophilic partners. To this end, a moderate scope of oxygen, nitrogen, and sulfur-based nucleophiles was demonstrated. During thermolysis of TMD, acetone is lost to form the acyl ketene. As this is a reversible reaction, an excess quantity of other ketones can be introduced to intercept this equilibrium to trap the acylketene to form diverse dioxinones and 8 examples of these derivatives are described ranging from good to excellent yields. (Scheme 7). Furthermore, isocyanates were able to trap the acylketene to form 1,3-oxazine-2,4-diones. A modest reaction scope of 5 examples was reported in moderate to excellent yields using either alkyl- or arylsubstituted isocyanate coupling partners.

\section{Microwave assisted generation of ketenes in flow}

Readily available $\alpha$-diazo carbonyl compounds are highly reactive molecules which can undergo loss of nitrogen by thermally, photochemically or catalytically induced Wolff rearrangements to afford ketenes [29]. While achievable under a variety of conditions with a wide substrate scope, there are complications with this reaction when considering scale up owing to the release of nitrogen gas at high temperatures.

In 2016, Ley and colleagues reported a new multi-faceted approach, whereby they employed a new single-mode bench-top resonator for the microwave-assisted flow generation of primary ketenes by thermal decomposition of $\alpha$-diazoketones at high temperature (Scheme 8) [30]. The authors introduced a flow stream of different $\alpha$-diazoketones in acetonitrile through a helical tubular borosilicate glass reactor in a microwave cavity at $1.0 \mathrm{~mL} / \mathrm{min}$. The cavity was heated to $165^{\circ} \mathrm{C}$ using $80 \mathrm{~W}$ of microwave irradiation. Initially, the resulting ketene products were trapped with amine nucleophiles affording the resulting amides in good yields. Subsequently, they explored the $[2+2]$ cycloaddition reaction with imines, further demonstrating the assembly of $\beta$-lactams using a fusion of two enabling technologies (flow and microwave synthesis). Notably, when the reactions were performed in standard sealed microwave vials, no desired products were formed. Furthermore, attempts to generate the ketenes through more conventional conductive heating, in flow using a stainless-steel coil, led to both lower conversion and poorer selectivity, thus demonstrating the efficiency of the fused microwave-flow set-up. 


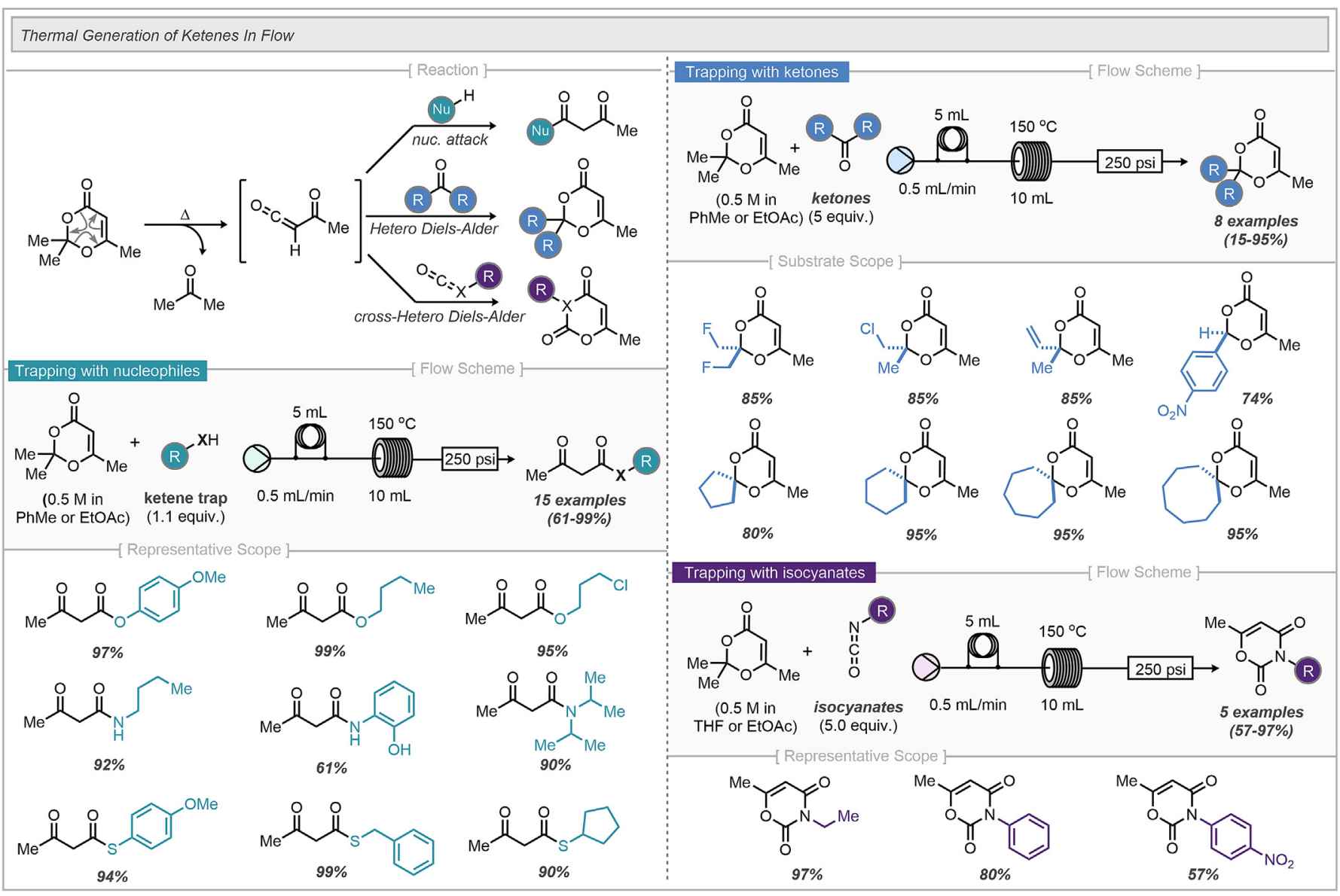

Scheme 7. Thermal generation of ketenes from TMD precursors.

\section{Photochemical generation of ketenes in flow}

The development of integrated photochemical reactors using continuous flow platforms has great benefits, enabling UV and visible light-mediated techniques to further exemplify and expand the chemical opportunities of flow chemistry. For example, continuous flow strategies can provide photoredox reactions with unique scale-up opportunities that have considerable industrial relevance.

Ketene generation and utility via flow photochemistry was first exploited by Konopelski in 2010, during the synthesis of trans- $\beta$ lactams from amino acid derivatives [31]. When employing a protected serine analogue bearing a diazo functionality, irradiation with either a mercury lamp or a compact fluorescent light (CFL) in a continuous flow set-up was shown to deliver the ketene intermediate (Scheme 9). This was intercepted (intramolecularly) by the pendant amine to form the $\beta$-lactam ring. Initial studies using the mercury lamp demonstrated that due to the thermal instability of the diazo analogue, the coiled reactor required additional external cooling. Despite slightly lower yields, when compared to the equivalent batch method ( $81 \%$ instead of $90 \%$ ), the shorter reaction time and ease of scale up rendered the modified continuous flow process the preferred method for this reaction. Furthermore, the alternative $100 \mathrm{~W}$ CFL showed far greater safety and lower cost than the traditional mercury light source and was notably the first example of the photochemical Wolff rearrangement using a CFL source. Pleasingly the reaction yield also increased whilst the product distributions were comparable in both batch and continuous flow. Additionally, the CFL-promoted reaction required no external cooling.

In 2012, Harrowven and co-workers described the photochemical manipulation of butenones to $5 \mathrm{H}$-furanones via an alkenylketene intermediate (Scheme 10) [32]. Interestingly, the authors disclose that these products (derived from formation of an endo $-\mathrm{OH}$ intermediate) are in stark contrast to the hydroxynaphthalene derivatives which predominate in a thermal reaction process 


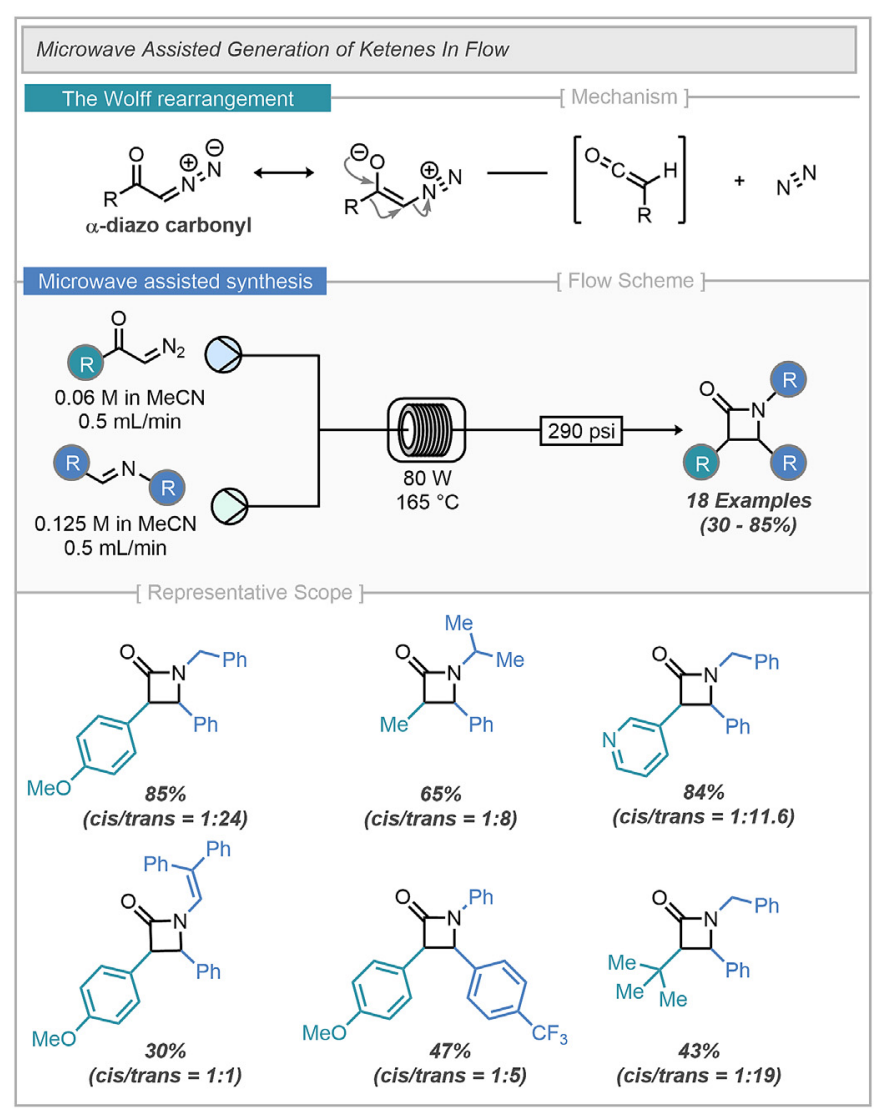

Scheme 8. Continuous flow microwave-enabled generation of ketenes.

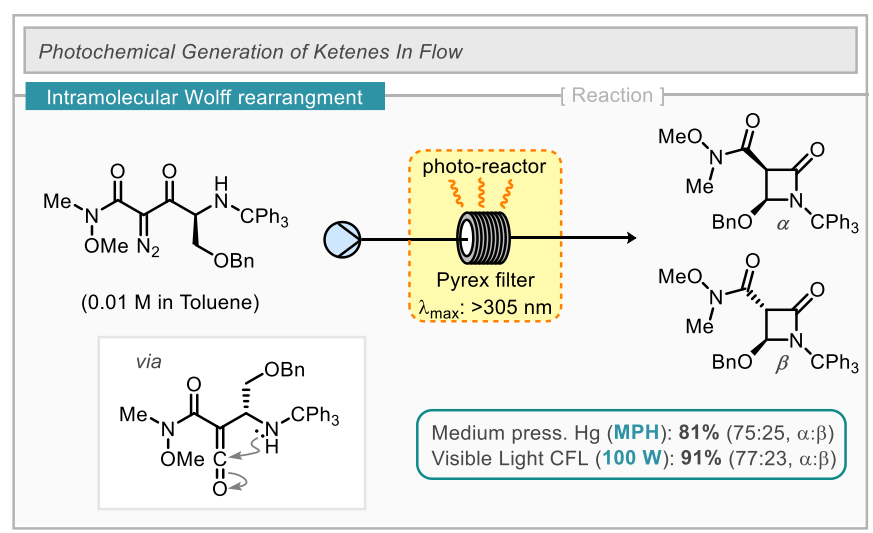

Scheme 9. Intramolecular trapping of photochemical Wolff rearrangement-generated ketenes.

(where the $-\mathrm{OH}$ group is situated exo). Experimental and computational mechanistic studies were employed to uncover an unselective photochemical pathway to the two intermediates. At this point internal trapping of the hydroxy group furnishes the $5 \mathrm{H}$ furanone in an energetically favourable process. However, under the photochemical protocol- the $\mathrm{OH}$ exo intermediate undergoes an electrocyclization to reform 2-hydroxybutenone starting material. This recycling loop leads to augmentation of the reaction pathway (Scheme 10) and to overall formation of the furanone product in up to $99 \%$ yield. The photo-flow system was also applied to a small library of 2-hydroxybutenone derivatives with excellent yields achieved throughout.

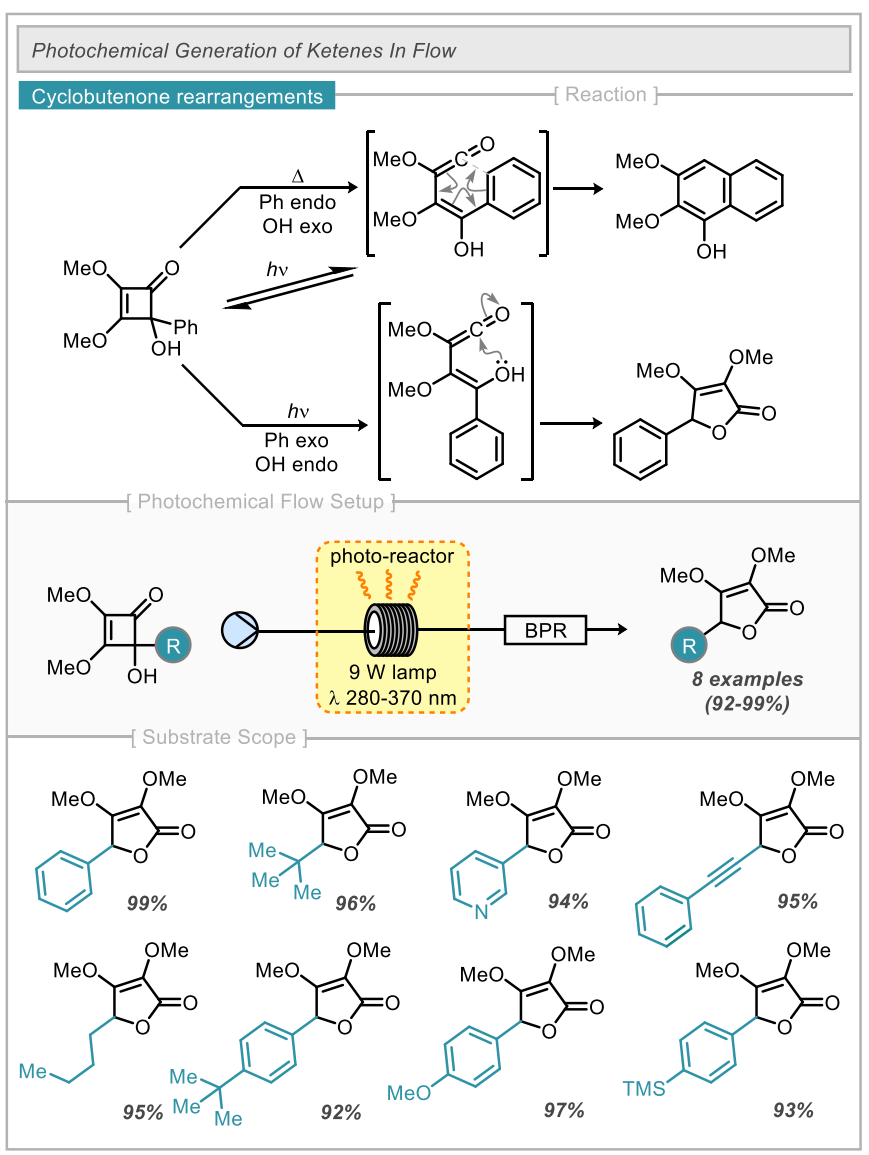

Scheme 10. Photochemical synthesis of $5 \mathrm{H}$-furanones via ketene intermediates generated in continuous flow.

The photo-initiated Wolff rearrangement in continuous flow has also been employed by Danheiser and colleagues, where they demonstrated (as part of a wider study also exploring thermal and batch methods) that $\alpha$-diazoenones could be coupled with ynamides to form 3-aminophenol derivatives (Scheme 11) [33]. The authors propose that this takes place - after an initial Wolff rearrangement - via an intramolecular [2 + 2] cycloaddition affording the amino-cyclobutenone intermediate, subsequent 4-electron electrocyclic cleavage, and finally a 6-electron electrocyclic ring closure to construct the aromatic ring. A small scope of aminophenols was then investigated using this photo-flow-initiated cascade sequence, with a specific focus on the creation of fused heteroaromatics such as indoles and benzothiophenes.

In 2014, Basso and co-workers described the photochemical activation of $\alpha$-diazoketone derivatives and downstream reactivity in what was described as a Ketene Three-Component Reaction (K3CR) (Scheme 12) [34]. Through coupling of the in situ-generated ketene structures with carboxylic acids and isocyanides, the authors demonstrated the efficient construction of $\alpha, \beta$-unsaturated amide derivatives. In a follow-up study they also exemplified the specific productivity of the continuous flow method with respect to batch alternatives, in this case, a 50-fold improvement (measured in $\mathrm{mmol} / \mathrm{Wx} 10^{-3}$ ) [35].

As part of a useful 4-step flow Arndt-Eistert homologation, Kappe and co-researchers described the application of UV irradiation in flow to perform the Wolff rearrangement, where the intermediate ketene formed in the process was subsequently hydrolysed to homologated amino acids (Scheme 13) [36]. Good reaction efficiency was demonstrated on a small subset of protected 


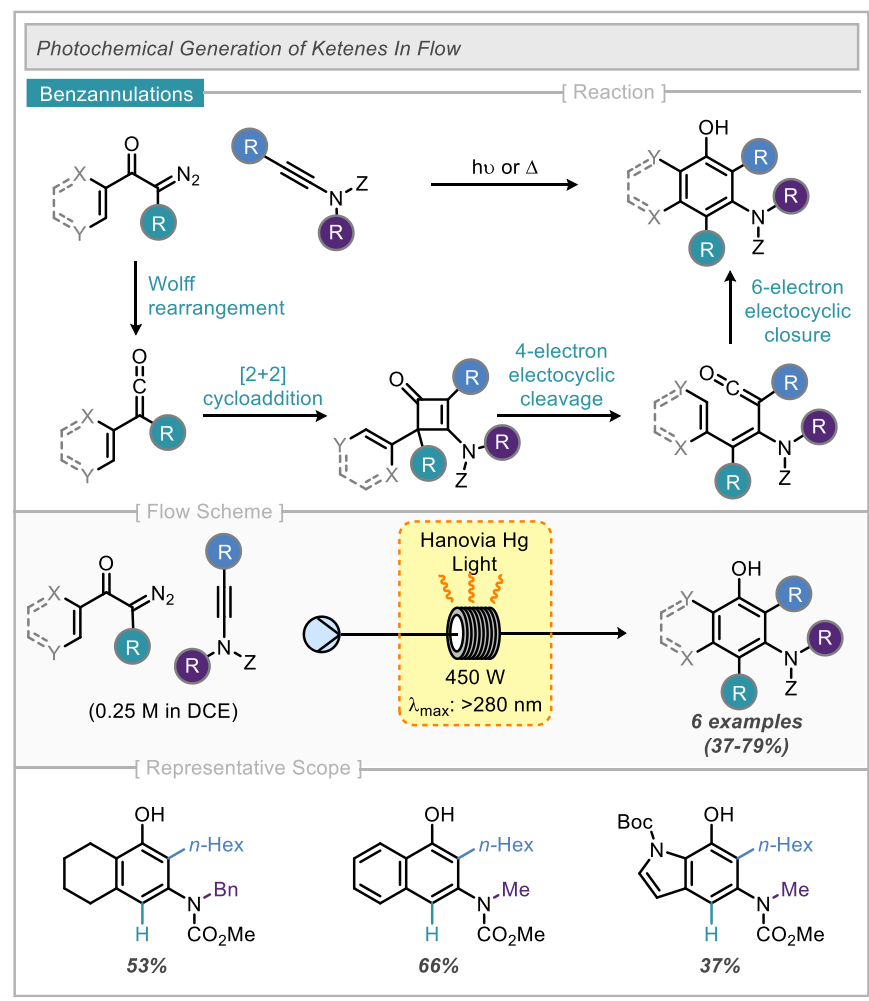

Scheme 11. Continuous flow synthesis of amino-phenols via a photochemical Wolffinitiated cyclisation cascade sequence.

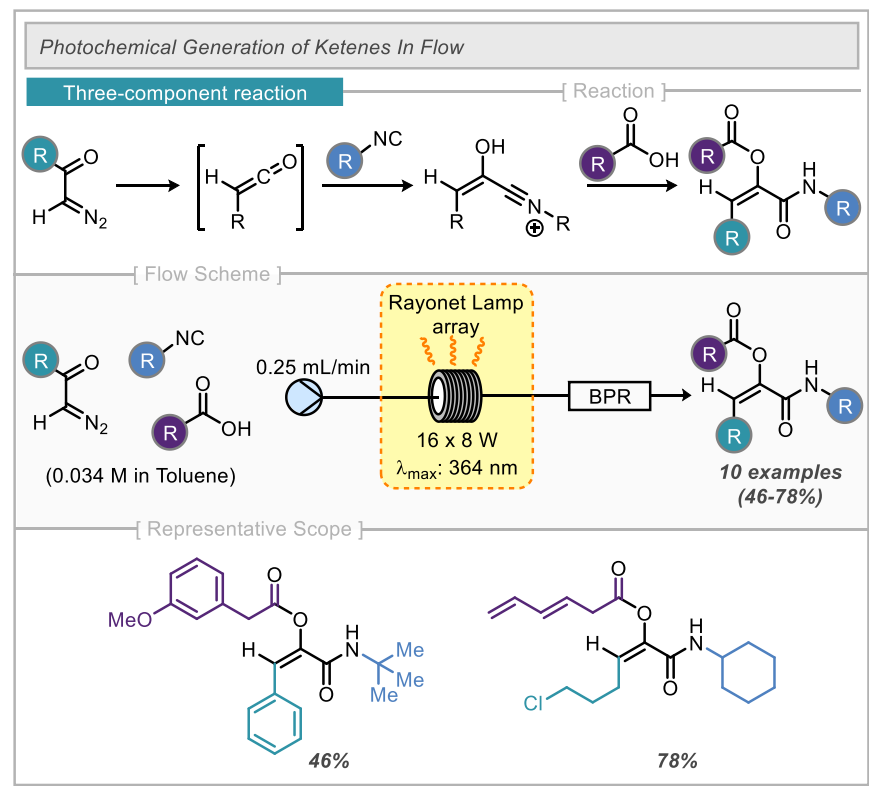

Scheme 12. Continuous flow photochemical three-component coupling.

natural $\alpha$-amino acids. Notably, the authors also reported a chemical alternative for the generation of the key ketene intermediate using a $\mathrm{Ag}_{2} \mathrm{O} / \mathrm{C}$ packed column, with impressive efficiency.

Finally, in 2014, Fuse and co-workers also made use of a photochemical Wolff rearrangement to generate a protected pentafluorophenyl ester in a continuous flow reactor [37]. This activated ester served as a key intermediate in the development towards the unnatural protected amino acid Alloc-D-Dph-OH,

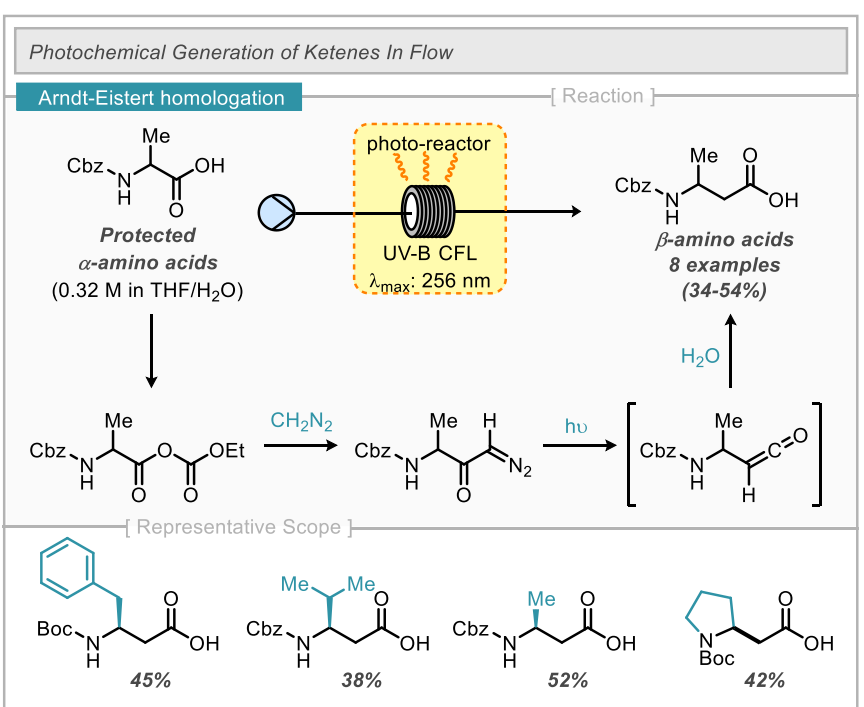

Scheme 13. Continuous flow Arndt-Eistert homologation of $\alpha$-amino acids.

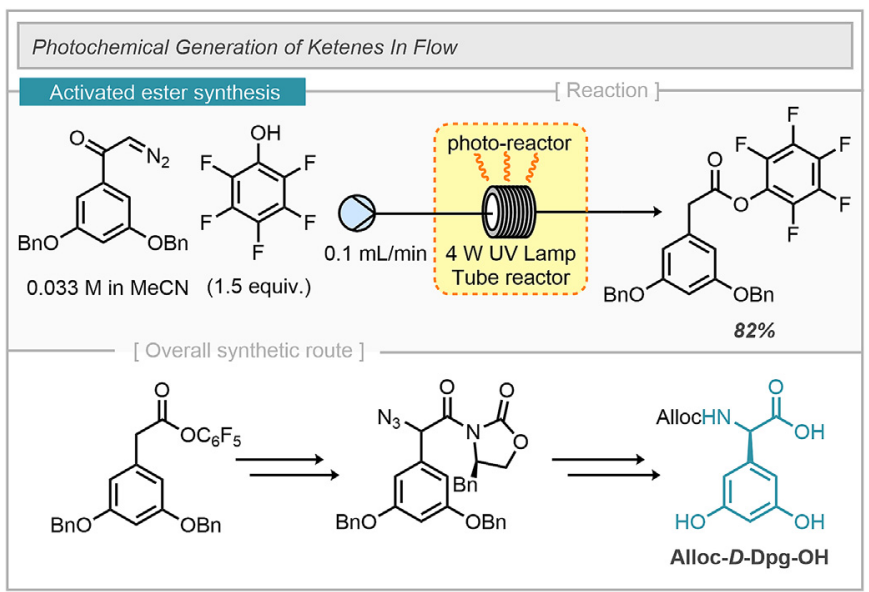

Scheme 14. Photochemical ester synthesis as key early step in complex molecule synthesis.

which has found utility in the synthesis of peptide antibiotics such as Vancoymycin and Feglymycin (Scheme 14).

\section{Conclusion}

In conclusion, the combination of continuous flow systems and reactive ketene species tells a symbiotic story; where development, implementation, and benchmarking of new thermal, photochemical, and microwave flow reactors has been challenged by the generation and exploitation of the versatile ketene functional group. Accordingly, these ketene intermediates have subsequently been leveraged towards diverse downstream reactivity, most commonly in acylation and cycloaddition methodology. New discoveries in continuous flow processing will continue to play an important part in the manipulation of sensitive intermediates and the ketene functional group will no doubt form part of these advances.

\section{Acknowledgement}

HRS thanks UCL for a studentship and generous support. JAL 
thanks the Leverhulme Trust for a research fellowship (RPG-2019260). TM thanks Cardiff University and EPSRC for a studentship (EP/ N509449/1). SVL acknowledges further support from the American Chemical Society through the Arthur C. Cope Award.

\section{References}

[1] M.S. Singh, Reactive Intermediates in Organic Chemistry, John Wiley \& Sons, Incorporated, 2014.

[2] H. Staudinger, Ber. Dtsch. Chem. Ges. 38 (1905) 1735-1739.

[3] A.D. Allen, T.T. Tidwell, Arkivoc (2016) 415-490.

[4] E. Wedekind, Ber. Dtsch. Chem. Ges. 34 (1901) 2070-2077.

[5] H. Staudinger, Chem. Ber. 40 (1907) 1145-1148.

[6] H. Staudinger, Justus Liebigs Ann. Chem. 356 (1907).

[7] T.T. Tidwell, Angew. Chem. Int. Ed. 44 (2005) 5778-5785.

[8] S.D. Roughley, A.M. Jordan, J. Med. Chem. 54 (2011) 3451-3479.

[9] L.M. Chapman, J.C. Beck, L. Wu, S.E. Reisman, J. Am. Chem. Soc. 138 (2016) 9803-9806.

[10] N. Fu, T.T. Tidwell, Tetrahedron 64 (2008) 10465-10496.

[11] W. Hanford, J. Sauer, Org. React. 3 (1946) 108-140.

[12] D.H. Paull, A. Weatherwax, T. Lectka, Tetrahedron 65 (2009) 6771-6803.

[13] S.E. Denmark, G.L. Beutner, Angew. Chem. Int. Ed. 47 (2008) 1560-1638.

[14] R.K. Orr, M.A. Calter, Tetrahedron 59 (2003) 3545-3565.

[15] E. Marquøs-lópez, M. Christmann, Angew. Chem. Int. Ed. 51 (2012) 8696-8698.

[16] A.D. Allen, T.T. Tidwell, Chem. Rev. 113 (2013) 7287-7342.

[17] M.B. Plutschack, B. Pieber, K. Gilmore, P.H. Seeberger, Chem. Rev. 117 (2017) $11796-11893$

[18] B.J. Deadman, S.G. Collins, A.R. Maguire, Chem. Eur J. 21 (2015) 2298-2308.

[19] A. Hafner, S. V Ley, Synlett 26 (2015) 1470-1474.
[20] N. Alonso, L.Z. Miller, J.M. Muñoz, J. Alcázar, D.T. McQuade, Adv. Synth. Catal. 356 (2014) 3737-3741.

[21] S. Karlsson, R. Bergman, C. Löfberg, P.R. Moore, F. Pontén, J. Tholander, H. Sörensen, Org. Process Res. Dev. 19 (12) (2015) 2067-2074.

[22] (a) J.A. Bull, R.A. Croft, O.A. Davis, R. Doran, K.F. Morgan, Chem. Rev. 116 (2016) 12150-12233:

(b) C.M. Marson, Chem. Soc. Rev. 40 (2011) 5514-5533;

(c) T.T. Talele, J. Med. Chem. 59 (2016) 8712-8756.

[23] J. Marchand-Brynaert, L. Ghosez, J. Am. Chem. Soc. 94 (1972) 2870-2872.

[24] C. Battilocchio, G. Iannucci, S. Wang, E. Godineau, A. Kolleth, A. De Mesmaeker, S. V Ley, React. Chem. Eng. 2 (2017) 295-298.

[25] C. Henry, D. Bolien, B. Ibanescu, S. Bloodworth, D.C. Harrowven, X. Zhang A. Craven, H.F. Sneddon, R.J. Whitby, Eur. J. Org Chem. (2015) 1491-1499.

[26] J. Sorensen, P. Erik, Reber Keith, S. Tilley, David, Chem. Soc. Rev. 38 (2009) 3022-3034.

[27] N.T.M. Wilsmore, F. Chick, J. Chem. Soc. Trans. 93 (1908) 946-950.

[28] R. Galaverna, T. Mcbride, J.C. Pastre, D.L. Browne, React. Chem. Eng 4 (2019) 1559-1564.

[29] H. Meier, K.-P. Zeller, Angew. Chem. Int. Ed. 14 (1) (1975) 32-43.

[30] B. Musio, F. Mariani, M.A. Kabeshov, H. Odajima, S. V Ley, Synthesis 48 (2016) $3515-3526$

[31] Y.S. Mimieux, M.E. Mahoney, J.P. Konopelski, D.L. Rogow, W.J. Mcdonald J. Am. Chem. Soc. 132 (2010) 11379-11385.

[32] D.C. Harrowven, M. Mohamed, T.P. Goncalves, R.J. Whitby, D. Bolien, H.F. Sneddon, Angew. Chem. Int. Ed. 51 (2012) 4405-4408.

[33] T.P. Willumstad, O. Haze, X.Y. Mak, T.Y. Lam, Y. Wang, R.L. Danheiser, J. Org. Chem. 78 (2013) 11450-11469.

[34] S. Garbarino, L. Banfi, R. Riva, A. Basso, J. Org. Chem. 79 (2014) 3615-3622.

[35] S. Garbarino, S. Protti, A. Basso, Synthesis 47 (2015) 2385-2390.

[36] V.D. Pinho, B. Gutmann, C.O. Kappe, RSC Adv, 4 (2014) 37419-37422.

[37] Y. Mifune, S. Fuse, H. Tanaka, J. Flow Chem. 4 (4) (2014) 173-179. 